\title{
Lipoprotein(a) Serum Levels in Diabetic Patients with Retinopathy
}

\section{Giulia Malaguarnera, ${ }^{1}$ Caterina Gagliano, ${ }^{2}$ Claudio Bucolo, ${ }^{1}$ Marco Vacante, ${ }^{3}$ Salvatore Salomone, ${ }^{1}$ Michele Malaguarnera, ${ }^{1}$ Daniela Giovanna Leonardi, ${ }^{3}$ Massimo Motta, ${ }^{3}$ Filippo Drago, ${ }^{1}$ and Teresio Avitabile ${ }^{2}$}

\author{
${ }^{1}$ International Ph. D. Program in Neuropharmacology, University of Catania, 95123 Catania, Italy \\ ${ }^{2}$ Department of Ophthalmology, University of Catania, 95123 Catania, Italy \\ ${ }^{3}$ Research Center "La Grande Senescenza", University of Catania, 95125 Catania, Italy
}

Correspondence should be addressed to Michele Malaguarnera; m.malaguarnera@email.it

Received 30 April 2013; Accepted 21 May 2013

Academic Editor: Ronald L. Klein

Copyright (C) 2013 Giulia Malaguarnera et al. This is an open access article distributed under the Creative Commons Attribution License, which permits unrestricted use, distribution, and reproduction in any medium, provided the original work is properly cited.

\begin{abstract}
Background. Atherogenic lipoproteins, such as total cholesterol, LDL cholesterol, oxidized low density lipoprotein, and triglycerides, are associated with progression of retinopathy. Aim. To evaluate the relationship between lipoprotein(a) and retinopathy in patients with type 2 diabetes mellitus. Materials and Methods. We enrolled 145 diabetic consecutive patients (82 females, 63 males; mean age $66.8 \pm 12$ years, mean duration of diabetes $9.4 \pm 6.8$ years). Presence and severity of retinopathy were evaluated. Serum lipid profile, including Lp(a) level, was assessed. Results. High Lp(a) levels have been observed in 54 (78.3\%) subjects and normal levels in $13(18.85 \%)$ subjects as regards diabetic patients with retinopathy. $L p(a)$ levels were high in 15 subjects (21.75\%) and normal in 63 subjects $(91.35 \%)$ as regards patients without retinopathy. Conclusions. Lp(a) levels are increased in a significant percentage of patients with retinopathy compared to diabetic patients without retinopathy. The impact of Lp(a) levels on diabetic retinopathy needs to be further investigated.
\end{abstract}

\section{Introduction}

In developed countries, diabetic retinopathy (DR) is the leading cause of vision loss in adults of working age [1]. The worldwide prevalence of diabetes was estimated to be $2.8 \%$ in 2000 and $4.4 \%$ in 2030 [2]. The prevalence rates of DR ranged from $7 \%$ to $12 \%$. Kempen et al. reported that approximately 4.1 million US adults 40 years and older have diabetic retinopathy [3]. Early identification and treatment are key priorities for reducing the morbidity of diabetic eye disease. Population and family studies have shown the pathogenesis of DR due to the interaction of several environmental, nutritional, and genetic risk factors [4]. The pathophysiology of DR is not completely understood at this time, but various biochemical pathways have been implicated, including polyol accumulation (via the enzyme aldose reductase), accumulation of advanced glycation end products, formation of reactive oxygen species, and activation of protein kinase $\mathrm{C}$ (PKC)
$[5,6]$. Risk factors for DR include hyperglycemia, hypertension, and dyslipidemia. It has been demonstrated that atherogenic lipoproteins, such as total cholesterol, LDL cholesterol, oxidized low density lipoprotein, and triglycerides, are associated with progression of retinopathy, proliferative retinopathy, and the development of macular oedema [7-9]. Lp(a) is a LDL like molecule consisting of an apolipoprotein B100 particle attached by a disulphide bridge to apo(a). Lp(a) plasma concentrations are highly heritable and mainly controlled by the apo(a) gene located on chromosome 6q26-27 [10]. The kringles of apo(a) are to a great extent a homologue of the kringle IV of plasminogen. Lp(a) competes with plasminogen in binding to fibrin and plasminogen receptors on the surfaces of monocytes and vascular endothelial cells, which may attenuate the generation of plasmin, and reduces fibrinolytic activity in blood circulation [11, 12]. Many prospective epidemiological studies have reported positive associations 
of $\mathrm{Lp}(\mathrm{a})$ concentration with cardiovascular diseases [13]. However, there are few and conflicting studies examining the relationship between lipoprotein(a) and retinopathy in patients with type 2 diabetes mellitus (DM).

\section{Methods and Materials}

2.1. Study Design. This study was carried out on patients with type 2 DM regularly attending our outpatients clinic at Cannizzaro Hospital in Catania. We enrolled 145 diabetic consecutive patients ( 82 females, 63 males; mean age $66.8 \pm 12$ years, mean duration of diabetes $9.4 \pm 6.8$ years). The exclusion criteria were (1) patients who were already on lipid lowering drugs or glitazones; (2) females taking oral contraceptive pills or hormone replacement therapy; (3) familial hypercholesterolemia; (4) hypothyroidism; (5) patients with chronic liver disease; (6) Patients with kidney disease. Assessment of DR was performed by ophthalmoscopy and/or biomicroscopy through dilated pupils by a retinal specialist, and fluorescein angiography was obtained when indicated. Examination of the retina was done through dilated pupils to determine the level of nonproliferative DR or proliferative DR. DR was graded as no retinopathy and minimum, moderate, or severe retinopathy as published elsewhere [14]. For the purpose of this study, the comparison between the groups of patients was performed according to the presence or absence of DR, regardless of its degrees of severity. All patients participating in this study gave their written informed consent.

2.2. Methods. Venous blood samples were drawn from patients, and all examinations were performed at $8.00 \mathrm{~h}$ after an overnight fast. The samples were allowed to clot, and serum was separated from the erythrocytes by centrifugation at $4^{\circ} \mathrm{C}$ and at $1500 \times \mathrm{g}$ for $15 \mathrm{~min}$. Total cholesterol, triglycerides, and fasting plasma glucose were enzymatically measured (Roche/Hitachi 912 analyzer; Roche Diagnostics, Switzerland). The fasting plasma glucose concentrations were assayed using the glucose-oxidase method with intra- and interassay CVs of $0.8 \%$ and $2.1 \%$, respectively. High density lipoprotein cholesterol (HDL-c) was measured enzymatically in the supernatant after precipitation of apolipoprotein Bcontaining lipoproteins by phosphotungstate/ $\mathrm{MgCl}_{2}$. Lowdensity lipoprotein (LDL) level was calculated by using Friedewald's formula [15]. Measurement of HbAlc was made by high-performance liquid chromatography (Menarini Diagnostics, Italy). Apolipoprotein A1 and B100 were measured by using nephelometric methods [16, 17]; Lp(a) was assayed by immunonephelometry (Olympus AU 640 Medican Watford UK). Coefficients of variance were 3\% and $4.2 \%$ for intra- and interassay variability, respectively. Lp(a) normal range in serum is up to $30 \mathrm{mg} / \mathrm{dL}$. Anthropometric measurements including weight, height, waist, and hip measurements were obtained using standardized techniques. Height was measured with a tape to the nearest centimetre. Subjects were requested to stand upright without shoes with their back against the wall, heels together, and eyes directed forward. Weight was measured with a traditional spring balance that was kept on a firm horizontal surface. Subjects were asked to
TABLE 1: Demographic characteristics of the study population.

\begin{tabular}{lc}
\hline \multicolumn{2}{c}{ Patients with type 2 diabetes mellitus $(n=145)$} \\
\hline Female/male & $82 / 63$ \\
Age (years) & $66.8 \pm 12.4$ \\
Smokers/no smokers & $92 / 53$ \\
BMI $\left(\mathrm{kg} / \mathrm{m}^{2}\right)$ & $26.4 \pm 2.2$ \\
Waist circumference $(\mathrm{cm})$ & $94.8 \pm 9.56$ \\
Hip circumference $(\mathrm{cm})$ & $96.8 \pm 8.44$ \\
Waist-to-hip ratio & $0.98 \pm 0.05$ \\
Systolic blood pressure $(\mathrm{mmHg})$ & $145.4 \pm 14.2$ \\
Diastolic blood pressure $(\mathrm{mmHg})$ & $84.6 \pm 9.8$ \\
\hline
\end{tabular}

wear light clothing, and weight was recorded to the nearest $0.5 \mathrm{Kg}$. Body mass index (BMI) was calculated by using the formula: weight $\left(\mathrm{Kg} /\right.$ height $\left.\left(\mathrm{m}^{2}\right)\right)$. Waist circumference was measured by using a nonstretchable measuring tape. The subjects were asked to stand erect in a relaxed position with both feet together on a flat surface; one layer of clothing was accepted. Waist girth was measured as the smallest horizontal girth between the costal margins and the iliac crest at minimal respiration. Hip was taken as the greatest circumference (the widest protrusion of the hip) on both sides; measurements were made to the nearest centimetre. Waist-to-hip ratio was calculated by dividing the waist circumference $(\mathrm{cm})$ by the hip circumference $(\mathrm{cm})$. Examination of the retina was done through dilated pupils to determine the level of nonproliferative DR, proliferative DR, and macular edema by qualified ophthalmologists (T.A.; C.G.). The definitions were based on the International Classification of Diabetic Retinopathy.

\section{Statistical Analysis}

Data were reported as median or mean \pm standard deviation for continuous variables and as proportions for categorical variables. Continuous variables were all analyzed by Student's $t$-test and for proportions $\chi^{2}$ test. Multiple logistic regression analysis was used to obtain the association between various indices and DR. A $P$ value $\leq 0.05$ was considered statistically significant.

\section{Results}

In our study 67 out of the 145 enrolled patients had DR (Table 1). The patients with DR had a longer duration of diabetes (13.8 versus 5.4 years; $P<0.01)$ and higher glycated haemoglobin levels $(10.2 \%$ versus $8.7 \% ; P<0.01)$ compared to subjects without DR. As regards diabetic management, 5\% of patients were on diet alone; $64 \%$ were on oral antidiabetic drugs, for example, metformin and/or sulfonylurea; $13 \%$ were on metformin + insulin; $10 \%$ were on sulfonylurea + insulin; $8 \%$ were on insulin alone. $\mathrm{Lp}(\mathrm{a})$ levels were measured in all subjects. We observed high Lp(a) levels in 54 (78.3\%) subjects and normal levels in 13 (18.85\%) subjects as regards diabetic patients with retinopathy. $\mathrm{Lp}$ (a) levels were high in 15 subjects $(21.75 \%)$ and normal in 63 subjects $(91,35 \%)$ as regards patients without retinopathy (Table 2 ). 
TABLE 2: Laboratory parameters of subjects included in the study.

\begin{tabular}{lccc}
\hline Parameter & $\begin{array}{c}\text { Patients with } \\
\text { retinopathy } \\
(n=67)\end{array}$ & $\begin{array}{c}\text { Patients } \\
\text { without } \\
\text { retinopathy } \\
(n=78)\end{array}$ & $P$ \\
\hline $\begin{array}{l}\text { Cholesterol total } \\
\text { (mmol/L) }\end{array}$ & $6.24 \pm 1.08$ & $5.87 \pm 0.96$ & $P=0.031$ \\
$\begin{array}{l}\text { Cholesterol HDL } \\
\text { (mmol/L) }\end{array}$ & $1.44 \pm 0.36$ & $1.36 \pm 0.30$ & $P=0.147$ \\
$\begin{array}{l}\text { Cholesterol LDL } \\
\text { (mmol/L) }\end{array}$ & $4.19 \pm 0.99$ & $3.87 \pm 0.95$ & $P=0.049$ \\
$\begin{array}{l}\text { Triglycerides (mmol/L) } \\
\text { Apolipoprotein A1 (g/L) }\end{array}$ & $1.67 \pm 0.76$ & $1.48 \pm 0.88$ & $P=0.170$ \\
$\begin{array}{l}\text { Apolipoprotein B (g/L) } \\
\text { Lipoprotein(a) (mg/dL) }\end{array}$ & $1.08 \pm 0.21$ & $1.47 \pm 0.20$ & $P=0.029$ \\
$\begin{array}{l}\text { Fasting plasma glucose } \\
\text { (mg/dL) }\end{array}$ & $172 \pm 28.2$ & $34.1 \pm 12.4$ & $P=0.000$ \\
HbAlc (\%) & $8.8 \pm 0.6$ & $7.2 \pm 0.7$ & $P=0.000$ \\
\hline
\end{tabular}

\section{Discussion}

Various epidemiological studies suggested that increased plasma $\mathrm{Lp}(\mathrm{a})$ is a strong and independent risk factor for cardiovascular disease $[18,19]$. The risk of developing cardiovascular disease is increased in diabetic individuals [20]. DR represents a common and severe complication of diabetes [21]; thus there is a need to implement effective strategies being able to prevent DR and to identify specific and early predictors. The etiology of DR is multifactorial, but reported risk factors include increased duration of diabetes mellitus, as well as severity of hypertension and hyperglycemia [22, 23]. In patients with type 2 diabetes the higher levels of total cholesterol, the LDL, and the Apo A1 can increase not only the cardiovascular disease but also the DR [24]. Circulating Lp(a) levels were increased in type 2 diabetic patients and positively correlated with blood concentrations of haemoglobin A1c. The higher glycated haemoglobin and the bed control of glycaemia may have important implications for the increased susceptibility to atherosclerosis. The majority of studies in type 2 diabetes found increased levels of $\mathrm{Lp}(\mathrm{a})$ in plasma with a few exception. Most studies reported that Lp(a) levels are unchanged in these patients [25-28]. Jenkins et al. [29] showed an increase of $\mathrm{Lp}(\mathrm{a})$ in type 2 diabetes with retinopathy. The potential causal relationship between lipoprotein(a) and retinopathy is still not clear. Elevated $\operatorname{Lp}(\mathrm{a})$ levels may play a causative role in DR by damaging the microcirculation. On the other hand, Rainwater et al. [30] have reported that Lp(a) concentrations were significantly lower in type 2 diabetes population compared to matched nondiabetic subjects. Since type 2 diabetes is characterized by hyperinsulinemia, this may contribute to a decrease in $\operatorname{Lp}(\mathrm{a})$ in these patients. Correlation between Lp(a) levels and macrovascular diseases was found in many studies in type 2 diabetes [31-34]. Beyond a role for $\mathrm{Lp}(\mathrm{a})$ in the macrovascular complication of diabetes, the existence of an association between elevated Lp(a) levels and microvascular diseases including DR and neuropathy has been studied. The existence of this relationship has been hypothesized based on the potential for $\operatorname{Lp}(\mathrm{a})$ to cause vessel damage through lipoprotein oxidation and on the potential antifibrinolytic and prothrombotic effects of $\mathrm{Lp}(\mathrm{a})$. Although some studies have shown a relationship between elevated $\mathrm{Lp}$ (a) levels and active retinopathy in patients with type 1 diabetes mellitus, a large prospective study failed to demonstrate this association $[29,33,35,36]$. In our study we observed that $\mathrm{Lp}(\mathrm{a})$ levels increased in a significant percentage of patients with retinopathy compared to diabetic patients without retinopathy. Limitations of our study are the modest size of the patients and the absence of separate models for men and women, due to the small numbers. Larger studies using more defined populations are required to better understand the relationship between $\operatorname{Lp}(\mathrm{a})$ concentrations and retinopathy in patients with type 2 diabetes mellitus. Although some studies have shown a relationship between elevated Lp(a) levels and active retinopathy in patients with type 1 diabetes mellitus, a large prospective study failed to demonstrate this association [33, 35]. Improved control of systemic metabolic factors is associated with reduced risks of microvascular complications, including retinopathy, and these benefits may persist longer than the period of intensive control, a phenomenon termed "metabolic memory" [37]. Unfortunately, microvascular complications may progress despite metabolic control representing an unfavourable type of metabolic memory. The mechanisms of metabolic memory are poorly understood, but various genetic and epigenetic influences have been suggested. In a case-control study on young type 1 diabetes patients, Gazzaruso et al. [36] showed high Lp(a) levels in patients with proliferative retinopathy compared to patients with nonproliferative or background retinopathy. No relationship with neuropathy was observed in this study, consistent with a large prospective study of complications in patients with type 1 diabetes mellitus, that failed to demonstrate a positive relationship between $\mathrm{Lp}(\mathrm{a})$ concentrations and diabetic nephropathy; this study also did not identify a relationship between plasma Lp(a) levels and the development of DR. In 412 Korean patients with type 2 diabetes, higher serum $\operatorname{Lp}(\mathrm{a})$ levels have been found in subject with proliferative DR versus those with either no DR or with nonproliferative DR [38]. In conclusion, Lp(a) levels may be increased in patients with retinopathy. $\mathrm{Lp}(\mathrm{a})$ is involved in the development of atherothrombosis and activation of acute inflammation exerting a proatherogenic and hypofibrinolytic effect. The impact of Lp(a) levels on DR needs to be further investigated by prospective studies and the assessment of apo(a) polymorphism.

\section{Conflict of Interests}

The authors declare that they have no conflict of interests.

\section{References}

[1] D. S. Jung and K. Park, "Posttraumatic bilateral internuclear ophthalmoplegia with exotropia," Archives of Neurology, vol. 61, no. 3, p. 429, 2004.

[2] S. Wild, G. Roglic, A. Green, R. Sicree, and H. King, "Global Prevalence of Diabetes: estimates for the year 2000 and projections for 2030," Diabetes Care, vol. 27, no. 5, pp. 1047-1053, 2004. 
[3] J. H. Kempen, B. J. O’Colmain, M. C. Leske et al., "The prevalence of diabetic retinopathy among adults in the United States," Archives of Ophthalmology, vol. 122, no. 4, pp. 552-563, 2004.

[4] R. S. Newfield, M. Polak, R. Marchase, and P. Czernichow, "Epidemiology and genetics of diabetic complications," Diabetologia, vol. 40, no. 3, pp. B62-B64, 1997.

[5] T. C. Hohman, C. Nishimura, and W. G. Robison Jr., "Aldose reductase and polyol in cultured pericytes of human retinal capillaries," Experimental Eye Research, vol. 48, no. 1, pp. 55-60, 1989.

[6] E. Duh and L. P. Aiello, "Vascular endothelial growth factor and diabetes: the agonist versus antagonist paradox," Diabetes, vol. 48, no. 10, pp. 1899-1906, 1999.

[7] T. J. Orchard, "Dyslipoproteinemia and diabetes," Endocrinology and Metabolism Clinics of North America, vol. 19, no. 2, pp. 361-380, 1990.

[8] M. D. Davis, "Worsening of diabetic retinopathy after improvement of glycemic control," Archives of Ophthalmology, vol. 116, no. 7, pp. 931-932, 1998.

[9] N. I. Uçgun, Z. Yildirim, N. Kiliç, and E. Gürsel, “The importance of serum lipids in exudative diabetic macular edema in type 2 diabetic patients," Annals of the New York Academy of Sciences, vol. 1100, pp. 213-217, 2007.

[10] G. Utermann, H. J. Menzel, H. G. Kraft, H. C. Duba, H. G. Kemmler, and C. Seitz, "Lp(a) glycoprotein phenotypes. Inheritance and relation to $\mathrm{Lp}(\mathrm{a})$-lipoprotein concentrations in plasma," Journal of Clinical Investigation, vol. 80, no. 2, pp. 458465, 1987.

[11] L. A. Miles, G. M. Fless, E. G. Levin, A. M. Scanu, and E. F. Plow, "A potential basis for the thrombotic risks associated with lipoprotein(a)," Nature, vol. 339, no. 6222, pp. 301-303, 1989.

[12] K. A. Hajjar, D. Gavish, J. L. Breslow, and R. L. Nachman, "Lipoprotein(a) modulation of endothelial cell surface fibrinolysis and its potential role in atherosclerosis," Nature, vol. 339, no. 6222, pp. 303-305, 1989.

[13] M. Malaguarnera, M. Vacante, C. Russo et al., "Lipoprotein(a) in cardiovascular diseases," BioMed Research International, vol. 2013, Article ID 650989, 9 pages, 2013.

[14] M. C. Leske, S. Wu, L. Hyman et al., "Diabetic retinopathy in a black population: the Barbados eye study," Ophthalmology, vol. 106, no. 10, pp. 1893-1899, 1999.

[15] W. T. Friedewald, R. I. Levy, and D. S. Fredrickson, "Estimation of the concentration of low-density lipoprotein cholesterol in plasma, without use of the preparative ultracentrifuge," Clinical Chemistry, vol. 18, no. 6, pp. 499-502, 1972.

[16] E. J. Schaefer and J. M. Ordovas, "Metabolism of apolipoproteins A-I, A-II, and A-IV," Methods in Enzymology, vol. 129, pp. 420443, 1986.

[17] J. M. Ordovas, J. P. Peterson, P. Santaniello, J. S. Cohn, P. W. F. Wilson, and E. J. Schaefer, "Enzyme-linked immunosorbent assay for human plasma apolipoprotein B," Journal of Lipid Research, vol. 28, no. 10, pp. 1216-1224, 1987.

[18] S. Lenzi, A. Scanu, and R. De Caterina, "Lipoprotein(a) as an athero-thrombotic risk factor: epidemiological evidence and possible pathogenetic mechanisms," Giornale Italiano di Cardiologia, vol. 26, no. 10, pp. 1203-1225, 1996.

[19] F. Galvano, M. Malaguarnera, M. Vacante et al., "The physiopathology of lipoprotein (a)," Frontiers in Bioscience, vol. 2, pp. 866-875, 2010.

[20] G. Steiner, "Dyslipoproteinemias in diabetes," Clinical \& Investigative Medicine, vol. 18, no. 4, pp. 282-287, 1995.
[21] L. Rampello, I. Vecchio, G. Battaglia, G. Malaguarnera, and L. Rampello, "Diabetic neuropathy. Elements of epidemiology and pathophysiology," Acta Medica Mediterranea, vol. 28, p. 219, 2012.

[22] R. F. Klein, K. R. Feingold, C. Morgan, W. H. Stern, and M. D. Siperstein, "Relationship of muscle capillary basement membrane thickness and diabetic retinopathy," Diabetes Care, vol. 10, no. 2, pp. 195-199, 1987.

[23] M. Rodriguez-Fontal, J. B. Kerrison, D. V. Alfaro, and E. P. Jablon, "Metabolic control and diabetic retinopathy," Current Diabetes Reviews, vol. 5, no. 1, pp. 3-7, 2009.

[24] P. Calmarza and J. C. Vella, "Lipids, lipoproteins and apolipoprotein (a) isoforms in type 2 diabetic patients," Journal of Cardiovascular Risk, vol. 6, no. 3, pp. 171-175, 1999.

[25] I. C. Klausen, F. E. Nielsen, L. Hegedus, L. U. Gerdes, P. Charles, and O. Faergeman, "Treatment of hypothyroidism reduces lowdensity lipoproteins but not lipoprotein(a)," Metabolism, vol. 41, no. 8, pp. 911-914, 1992.

[26] L. C. Ramirez, C. Arauz-Pacheco, C. Lackner, G. Albright, B. V. Adams, and P. Raskin, "Lipoprotein (a) levels in diabetes mellitus: relationship to metabolic control," Annals of Internal Medicine, vol. 117, no. 1, pp. 42-47, 1992.

[27] A. Pérez, G. Carreras, A. Caixàs et al., "Plasma lipoprotein(a) levels are not influenced by glycemic control in type 1 diabetes," Diabetes Care, vol. 21, no. 9, pp. 1517-1520, 1998.

[28] S. M. Haffner, K. K. Gruber, P. A. Morales et al., "Lipoprotein(a) concentrations in Mexican Americans and non-Hispanic whites: the San Antonio Heart Study," American Journal of Epidemiology, vol. 136, no. 9, pp. 1060-1068, 1992.

[29] A. J. Jenkins, J. S. Steele, E. D. Janus, J. D. Santamaria, and J. D. Best, "Plasma apolipoprotein (a) is increased in Type 2 (noninsulin-dependent) diabetic patients with microalbuminuria," Diabetologia, vol. 35, no. 11, pp. 1055-1059, 1992.

[30] D. L. Rainwater, J. W. MacCluer, M. P. Stern, J. L. VandeBerg, and S. M. Haffner, "Effects of NIDDM on lipoprotein(a) concentration and apolipoprotein(a) size," Diabetes, vol. 43, no. 7, pp. 942-946, 1994.

[31] M. A. Gall, P. Rossing, E. Hommel et al., "Apolipoprotein(a) in insulin-dependent diabetic patients with and without diabetic nephropathy," Scandinavian Journal of Clinical and Laboratory Investigation, vol. 52, no. 6, pp. 513-521, 1992.

[32] M. M. Ritter, M. Loscar, W. O. Richter, and P. Schwandt, "Lipoprotein(a) in diabetes mellitus," Clinica Chimica Acta, vol. 214, no. 1, pp. 45-54, 1993.

[33] R. E. Maser, C. Laudadio, and G. S. DeCherney, "The effects of age and diabetes mellitus on nerve function," Journal of the American Geriatrics Society, vol. 41, no. 11, pp. 1202-1204, 1993.

[34] J. M. Taupin, V. Durlach, M. Hassaim et al., "Lipoprotein (a) and diabetes: correlations based on 224 case histories," Diabete et Metabolisme, vol. 19, no. 2, pp. 250-256, 1993.

[35] M. Maioli, G. Tonolo, A. Pacifico et al., "Raised serum apolipoprotein (a) in active diabetic retinopathy," Diabetologia, vol. 36, no. 1, pp. 88-90, 1993.

[36] C. Gazzaruso, A. Garzaniti, P. Buscaglia et al., "Lipoprotein(a) levels and apolipoprotein(a) polymorphism in type 1 diabetes mellitus: relationships to microvascular and neurological complications," Acta Diabetologica, vol. 35, no. 1, pp. 13-18, 1998.

[37] L. Zhang, B. Chen, and L. Tang, "Metabolic memory: mechanisms and implications for diabetic retinopathy," Diabetes Research and Clinical Practice, vol. 96, no. 3, pp. 286-293, 2012. 
[38] C. H. Kim, H. J. Park, J. Y. Park, S. Hong, Y. Yoon, and K. Lee, "High serum lipoprotein(a) levels in Korean type 2 diabetic patients with proliferative diabetic retinopathy," Diabetes Care, vol. 21, no. 12, pp. 2149-2151, 1998. 


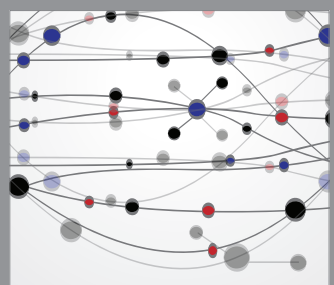

The Scientific World Journal
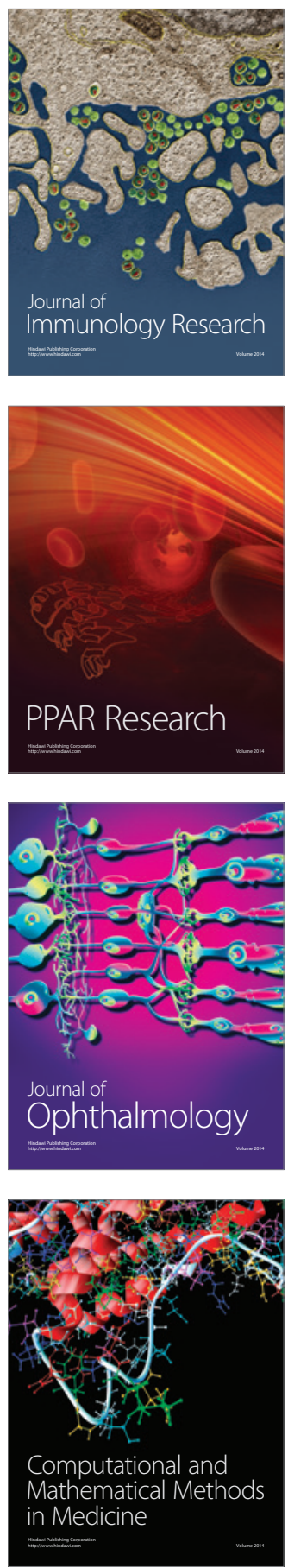

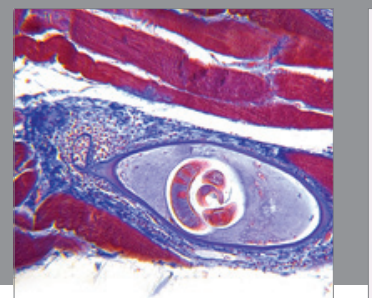

Gastroenterology

Research and Practice
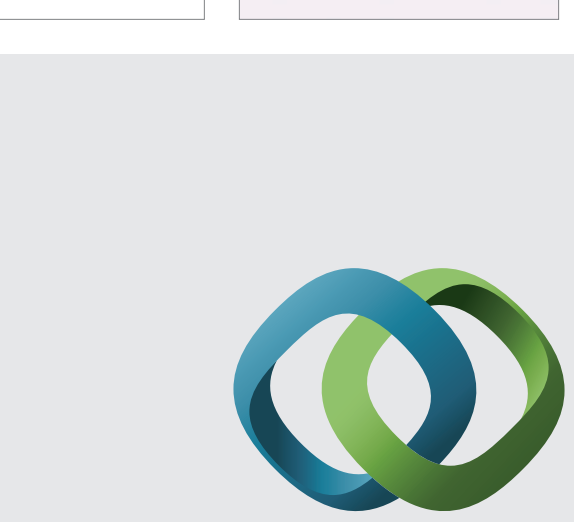

\section{Hindawi}

Submit your manuscripts at

http://www.hindawi.com
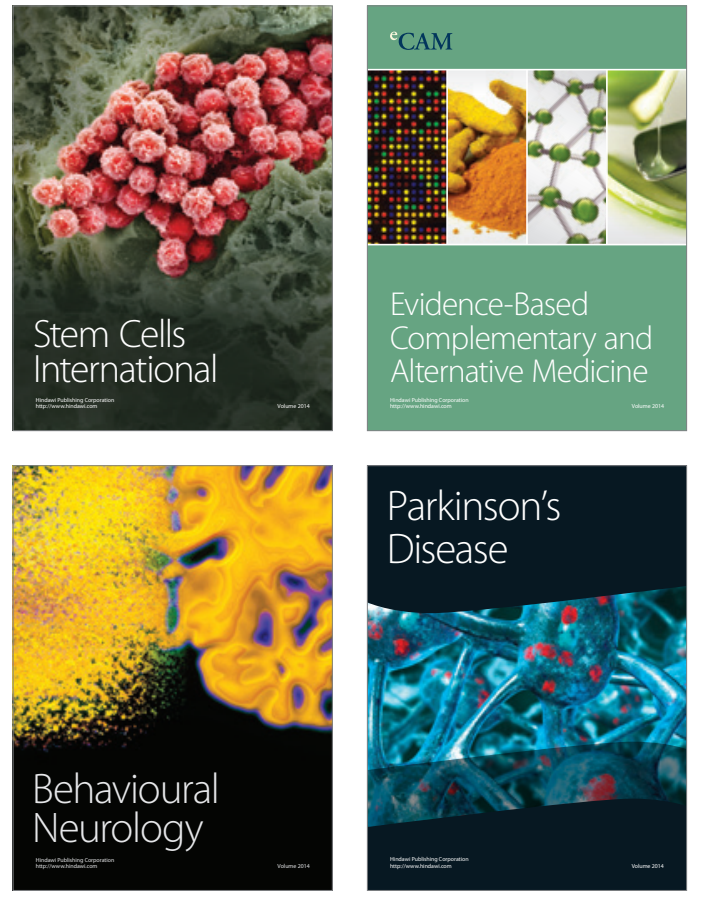
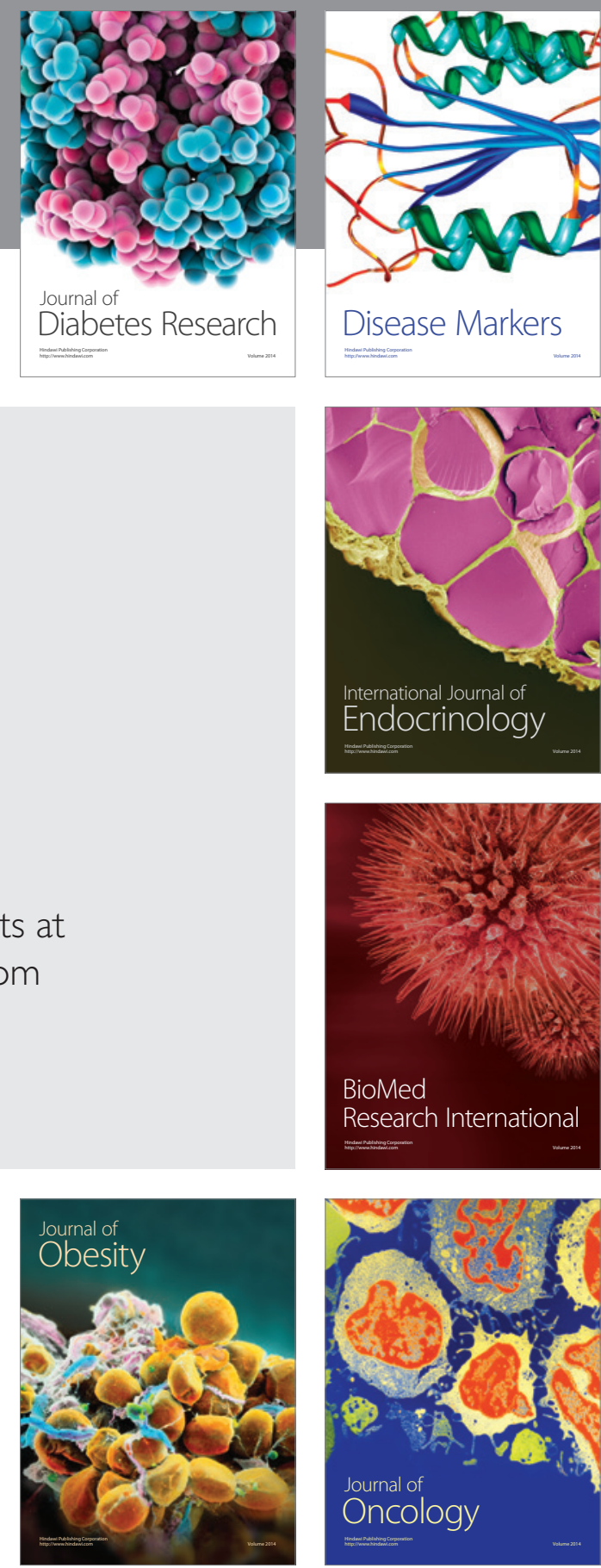

Disease Markers
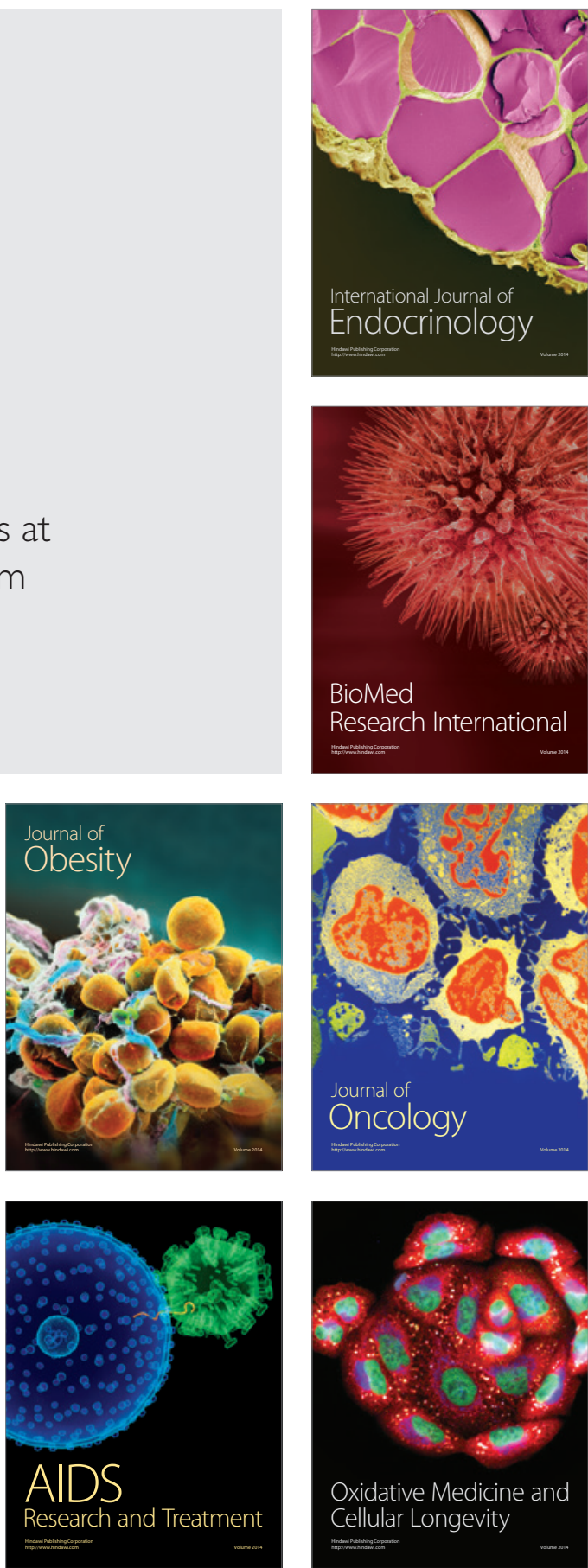